\title{
Microphysical characteristics of cumulus clouds as observed in some African countries
}

\author{
Rabia Merrouchi ${ }^{1,2}$ \\ ${ }^{1}$ National Meteorological service of Morocco, Casablanca, BP 8106, Morocco \\ ${ }^{2}$ Faculty of science Ben M'sick, Casablanca, Morocco \\ E-mail: Rabia.merrouchi@gmail.com
}

\begin{abstract}
This paper analyses airborne measurements of several midlevel and mixed-phase cumulus clouds observed in different environments (maritime, continental, shallow and deep convection) obtained during the scientific experiments performed by national weather modification programs in Morocco and Burkina Faso. Three cases are documented in this paper presenting the synoptic meteorological situation leading to the formation and the development of the sampled clouds and the results of the measurements collected using instrumental aircrafts. Several passes were made at the top of the sampled clouds and reported data were collected and analysed describing the variability of the measured parameters at various altitudes and thus different temperature values (negative and positive temperatures). The dependency of the liquid water content to the temperature has been studied but also its variation with regard to the vertical velocity and to the total concentration number of cloud particles.
\end{abstract}

Keywords: Aircraft Measurements, Cloud Microphysics, Liquid Water Content, West African Monsoon.

\section{Introduction}

Climate simulations are very sensitive to cloud microphysics. Changes in cloud microphysical parameters depend on thermodynamical and dynamical conditions, and aerosol-cloud interactions. Small changes in the particle size, shape, concentration, and mass can affect incoming and outgoing radiation, and this leads to significant changes in the earth-atmosphere energy budget (GULTEPE 2004) which result in a large uncertainty in climate simulations (Gultepe and Isaac 1996; Randall et al. 1998; Gultepe and Isaac 2002).

Better understanding of the microphysical structures of clouds in the atmosphere is essential for more accurate weather radar, lidar, satellite retrievals, climate/weather numerical modelling, and even aviation safety issues regarding icing conditions (Fleishauer et al., 2002). However, an accurate estimate of liquid and ice phase hydrometeors in the clouds is still very challenging, and our limited knowledge of cloud microphysical structures and characteristics has caused clouds to be poorly represented in weather/climate models and satellite retrievals. In general, quantitative studies of cloud phase-composition and distribution in numerical modelling have been significantly limited by a lack of intensive in-situ measurements that can directly evaluate the simulated results.

Literature on the structure of midlevel or mixed-phase clouds is relatively sparse at the international level and is rare in Africa. However, during the last decade, special interest was brought to the observation of mesoscale clouds and Saharan and anthropogenic aerosols forming in sub-tropical and tropical areas in Africa. Such information is not only important for the best understanding of cloud microphysics and precipitation processes and the impact of their variability on the western African nations but it's also important at the large scale seeing that central European countries are affected by the transport of dust aerosols forming in African Sahara. Moreover, some squall lines forming over the West African countries during the monsoon season and moving from east to west continue their development while crossing the Atlantic sea to form cyclones affecting Caribbean islands and west coasts of United States of America.

In this paper, we describe an observational study of some mixedphase cumulus clouds that was completed during the scientific activities of national weather modification programs on Morocco and Burkina Faso using instrumental aircrafts.

The first studied case concerns a shallow convective maritime cumulus congestus clouds forming at the vicinity of the north Atlantic coasts of Morocco while the two other cases describe the microphysical structure of deep convective and continental congestus cumulus clouds forming in the central part of Burkina Faso the monsoon season.

The aim of this study is to characterize the microphysical structure of midlevel mixed-phase clouds forming in different environments (maritime and continental, shallow and deep convection) in order to mold a conceptual picture of the microphysical and thermodynamic mechanisms that drive this kind of convective clouds. To that end, we will review the instrumentation and aircraft sampling strategy, discuss the synoptic situations, present the measurements, and compare our case studies with prior and posterior observations by other authors.

\section{Aircraft measurement instrumentation}

Observations of microphysical cloud characteristics were obtained using instrumental airacrafts dedicated to weather modification activities in Morocco and Burkina Faso. Each of the two aircrafts King Air 100 and 200 used respectively by the national weather 
modification program of Morocco and Burkina Faso was equipped with a set of instruments including an FSSP-100 probe for sizing particles in the range of 2-44 $\mu \mathrm{m}$, an optical array probe (OAP)2DC probe for imaging cloud particles in the range of $25-800 \mu \mathrm{m}$, a Droplet Measurement Technologies (DMT) hot-wire instrument to measure liquid water contents (LWC), temperature and dewpoint probes and a Ball variometer for the inference of cloud drafts.

In addition, an integrated static pressure transducer provided pressure altitude measurements and a differential pressure transducer provided measurements of airspeed.

Temperature measurements were obtained using a Rosemount Model 102 de-iced platinum resistance-type total temperature sensor capable of measuring temperatures from $-50^{\circ}$ to $+50^{\circ} \mathrm{C}$, with an accuracy of $\pm 0.5^{\circ} \mathrm{C}$ and a response time constant of $1 \mathrm{~s}$

The dewpoint temperature was obtained using a General Eastern optical dewpoint sensor. Accuracy is stated by the manufacturer to be $\pm 0.25^{\circ} \mathrm{C}$ and the response time is quoted as $1^{\circ} \mathrm{C} \mathrm{s}^{-1}$. A DMT LWC-100 was used to measure liquid water concentrations from 0 to $5 \mathrm{~g} \mathrm{~m}^{-3}$ with an accuracy of $\pm 0.2 \mathrm{~g} \mathrm{~m}^{-3}$ and a response time of $50 \mathrm{~ms}$.

The Ball Variometer BV4.0 is a transducer that measures the vertical velocity of the aircraft up to $20 \mathrm{~m} \mathrm{~s}^{-1}$. The BV4.0 is interfaced with the aircraft pitot-static system.

All data collected from those equipments were recorded using a Science Engineering Associates (SEA) Model M200 data acquisition system.

Ground calibrations and comparisons with meteorological observations of the airport meteorological offices were conducted for checks of accuracy for state parameters. Calibration of optical probes measuring drop size distribution was made, at the ground, using glass beads.

The King Air 100 research aircraft of the national weather modification program had an additional probes consisting on the Precipitation Probe 2D2-P detecting large precipitation particles ranging between 200 and $6400 \mu \mathrm{m}$ and the passive cavity aerosol spectrometer probe that measures particles from 0.10 to 3.00 microns in diameter.

\section{Results and discussion}

\subsection{Case study of weak convective clouds forming near Moroccan oceanic coasts}

In this case study, is reported below a description of the weather situation leading to the development of maritime convective warm clouds near of the Atlantic coasts and to the formation of convective clouds associated to moderate air instability at the vicinity of Atlas Mountains and in the Eastern part of the Moroccan country. Flight information and collected data are also documented.

\subsubsection{Description of the synoptic meteorological situation}

The Day of February 15, 2004 was characterized by the presence of a low pressure area (Fig.2), associated to a minimum of thermal conditions, moving from West to East and affecting the north part of the Moroccan country. The low pressure area is visible at the surface and also in the different altitude layers from the ground surface to the pressure level of $500 \mathrm{Hpa}$.

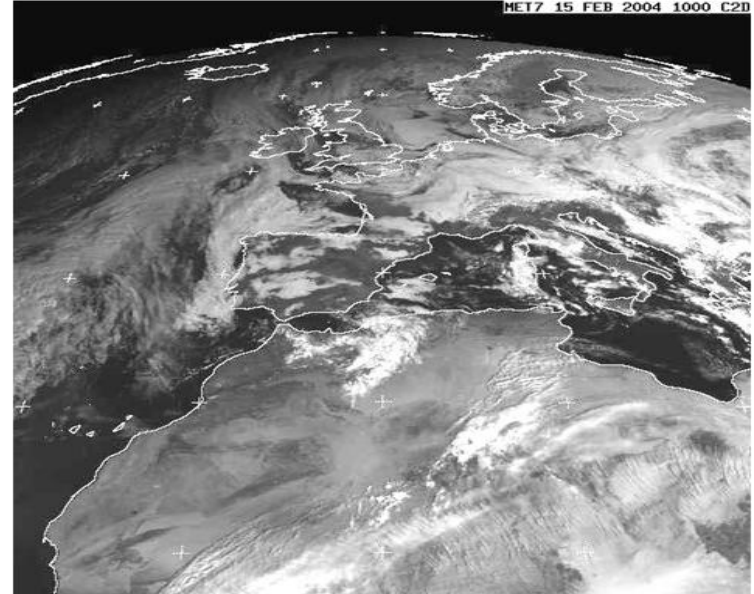

Fig. 1: Eumetsat Infrared Satellite Image of February 15 À10h00

Lightning and moderate convective rainfalls were observed during the night time in the most part of the north Atlantic coasts and adjacent plains. In the morning, light rains resulted from residual instability in the lower atmosphere were observed in the north western Atlantic coasts and in the interior at the vicinity of Atlas Mountains (Fig.1). During the afternoon, the said low pressure area moved to Algeria leading to more stable weather over the Moroccan country associated to height pressure conditions coming from Atlantic Ocean and reaching the country by the Southwest.

Outputs of the atmospheric numerical model and especially those of the ALADIN (Atmospheric Limited Area Dynamic Adaptation International Development) high resolution numerical model were very consistent with the observed atmospheric conditions. For the morning of this day, results shows the development of convective clouds, in the North West Atlantic coasts, with a weak vertical extension due to the presence of a marked subsidence at the pressure level $700 \mathrm{hPa}$ ( $\approx$ an altitude of $3000 \mathrm{~m})$.

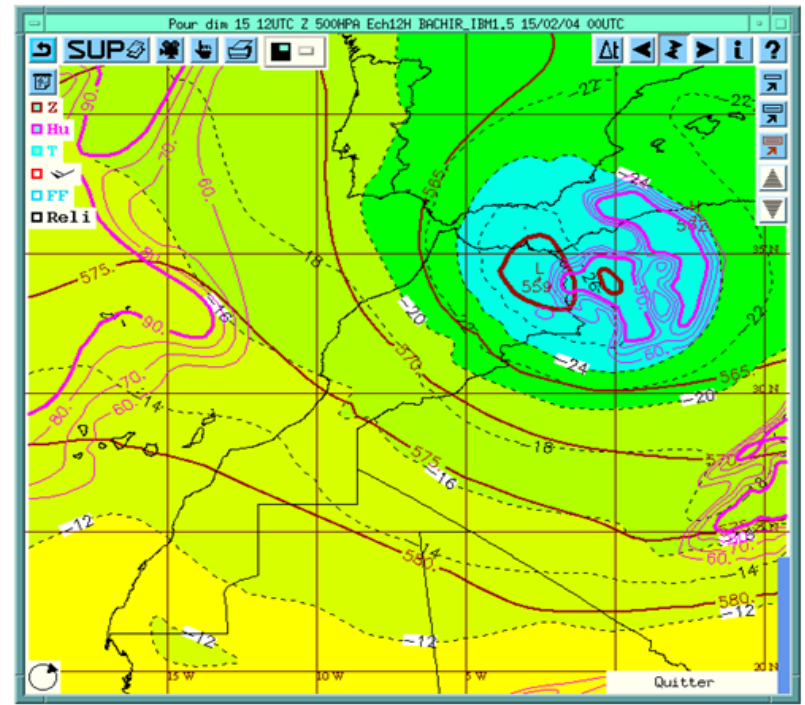

Fig. 2: Aladin Atmospheric Numerical Model Forecast Chart for the Day February 15, 2004 at Noon and for the Pressure Level of (500hpa) Illustrating the Low Pressure Area (5590 Mgp) Associated To Lower Temperature Values $\left(-26^{\circ} \mathrm{C}\right)$ and Hight Humidity Values (Superior To $\left.90 \%\right)$ Located at the Eastern Part of Morocco and Moving East to Algeria. (Black Solid Line: A Spatial Representation of Isolines of the Geopotential Field (In Mgp), Dashed Lines and Color Filling for Temperature (in ${ }^{\circ} \mathrm{C}$ ) and Solid Purple Lines for Air Humidity (in \%)) (Source: National Meteorological Service of Morocco)

\subsubsection{Flight information}

Take-off took place at 10:35 AM taking as a target the congestus cumulus clouds located at a distance of $40 \mathrm{~km}$ from Kenitra airport on radial $130^{\circ}$ (Fig.3). The cloud base was observed at about $700 \mathrm{~m}$ above the ground and the summit of the clouds at $3300 \mathrm{~m}$. 
The operation consisted on four penetrations into the cloud at temperatures between $-4^{\circ} \mathrm{C}$ and $0^{\circ} \mathrm{C}$ to determine the cloud microphysics characteristics in this part of cloud where supercooled water droplets exists.

The speed of the aircraft had an average of $86 \mathrm{~m} / \mathrm{s}$ during the cloud penetration.

At the end of the last pass, the plane flew down near the cloud base where suspended fine drops of rain were visible below the cloud base.

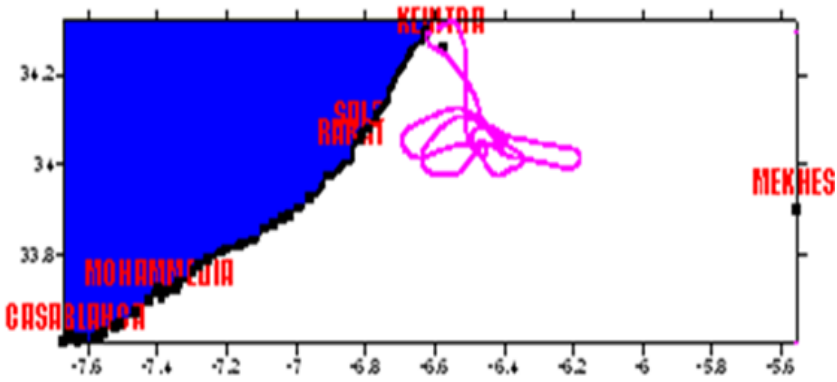

Fig. 3: A Plot of the Flight Tracks for the Flight of February 15, 2004.

\subsubsection{Evolution of cloud microphysical parameters}

Statistics of the various microphysical parameters collected during each pass are summarized in Table 1 . The temperature was generally between $-4.6^{\circ} \mathrm{C}$ and $-0.5^{\circ} \mathrm{C}$ and the mixing ratio had an average of $3.34 \mathrm{~g} / \mathrm{kg}$ with a maximum of $5 \mathrm{~g} / \mathrm{kg}$ observed during the first pass.

The liquid water content had an average of $0.6 \mathrm{gm}^{-3}$ and a maximum value of $1.9 \mathrm{gm}^{-3}$ which is an important value for these kind of convective clouds associated to a shallow convection. The FSSP total concentration number of cloud particles was generally less than 300 per $\mathrm{cm}^{-3}$ of air and the number of precipitable water drops, measured by the 2DC probe, has an averaged total concentration number of 120 per liter of air with a maximum value of 397 per liter.

Fig.4 shows the evolution of liquid water content, temperature and mixing ratio during the cloud penetrations. It appears clear that the increase of liquid water content is accompanied by a decrease in temperature and an increase of mixing ratio.

The vertical velocities were weak to moderate fluctuating between $-5.3 \mathrm{~m} / \mathrm{s}$ and $5.45 \mathrm{~m} / \mathrm{s}$. Updraft areas Coincides with areas of increased liquid water content.

The total concentration number of cloud particles was generally less than 300 per $\mathrm{cm}^{-3}$ with an average concentration of $115 \mathrm{~cm}^{-3}$. This result is consistent with similar values reported by Wallace (2006) for a maritime cumulus placing the number of cloud particles between 100 and $200 \mathrm{~cm}^{-3}$ and approximate estimates of Rosenfeld et al., (2006) reported during similar operations in $\mathrm{Ar}$ gentina.

Table 1: Statistics (Min, Max and Geometrical Mean) of the Different Microphysical Parameters Collected During Four Cloud Penetrations (nc: Total Concentration Number of Cloud Droplet Measured by the FSSP Probe in the Range of 2-44 mm and np the Total Concentration Number of Precipitation Water Drops Measured by the 2DC Probe in the Range of $25-800 \mathrm{~mm}$ )

\begin{tabular}{lllllll} 
Pass & $\mathrm{T}\left({ }^{\circ} \mathrm{C}\right)$ & $\begin{array}{l}\text { Mixed } \\
\text { Ratio } \\
(\mathrm{g} / \mathrm{Kg})\end{array}$ & $\begin{array}{l}\text { LWC } \\
\left(\mathrm{g} / \mathrm{m}^{3}\right)\end{array}$ & $\begin{array}{l}\text { Nc- } \\
\text { FSSP } \\
\left(\mathrm{cm}^{-3}\right)\end{array}$ & $\begin{array}{l}\text { Np - } \\
\text { 2DC } \\
\left(\text { litre }^{-1}\right)\end{array}$ & $\begin{array}{l}\text { Vertical } \\
\text { air speed } \\
(\mathrm{m} / \mathrm{s})\end{array}$ \\
\hline & -4.6 & 1.25 & - & - & - & -5.3 \\
P1 & -3.0 & 5.01 & 1.9 & 301.1 & 397.9 & +5.45 \\
& -4.25 & 2.96 & 0.31 & 111.3 & 94.66 & - \\
& -3.2 & 1.98 & - & - & - & -3.53 \\
P2 & -0.5 & 4.83 & 1.7 & 299.7 & 389.6 & +5.36 \\
& -2.58 & 3.88 & 0.69 & 145.10 & 144.44 & - \\
P3 & -2 & 2.95 & - & - & - & -4.52 \\
& 0.1 & 4.53 & 2 & 253.7 & 327.10 & +3.62 \\
& -0.61 & 3.82 & 0.87 & 138,73 & 124.49 & - \\
P4 & -4.4 & 2.28 & - & - & - & -7.45 \\
& -1.8 & 3.66 & 1.5 & 198 & 316.8 & +3.52 \\
& -3.43 & 3.31 & 0.47 & 77.61 & 121.48 & - \\
\hline
\end{tabular}

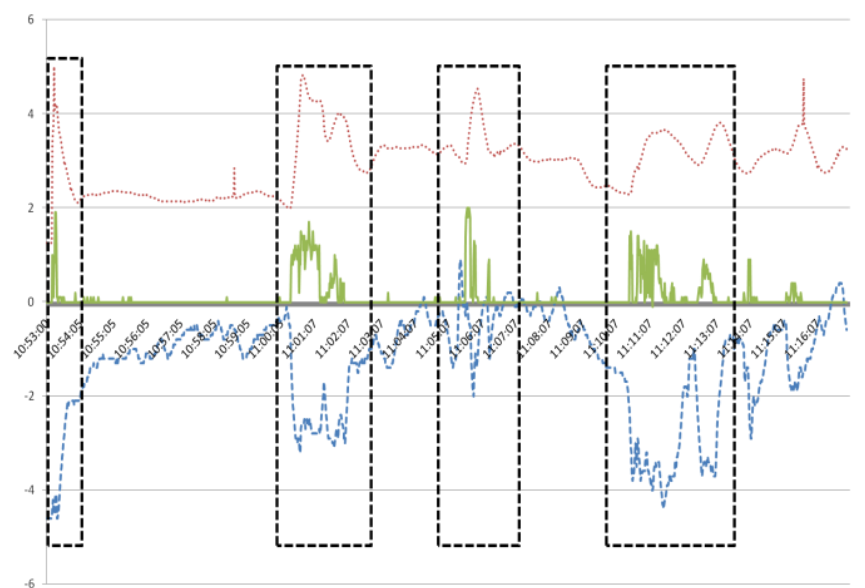

Fig. 4: Evolution of Liquid Water Content (Solid Green Line), Temperature (Dashed Blue Line) and Mixing Ratio (Dotted Red Line) During the Four Passes in the Cumulus Congestus Cloud

The confrontation between the two curves of the evolution of the liquid water content and the total concentration of cloud particles captured by the sensor FSSP (Fig.5) shows a perfect correspondence between the variations of the two respective parameters. Similar results were published by Warner (1969) for an isolated cumulus clouds over the east coast of Australia or by Blyth and Latham (1990) when crossing a cumulus cloud over Montana (USA) and by Rogers \& Yau (1996).

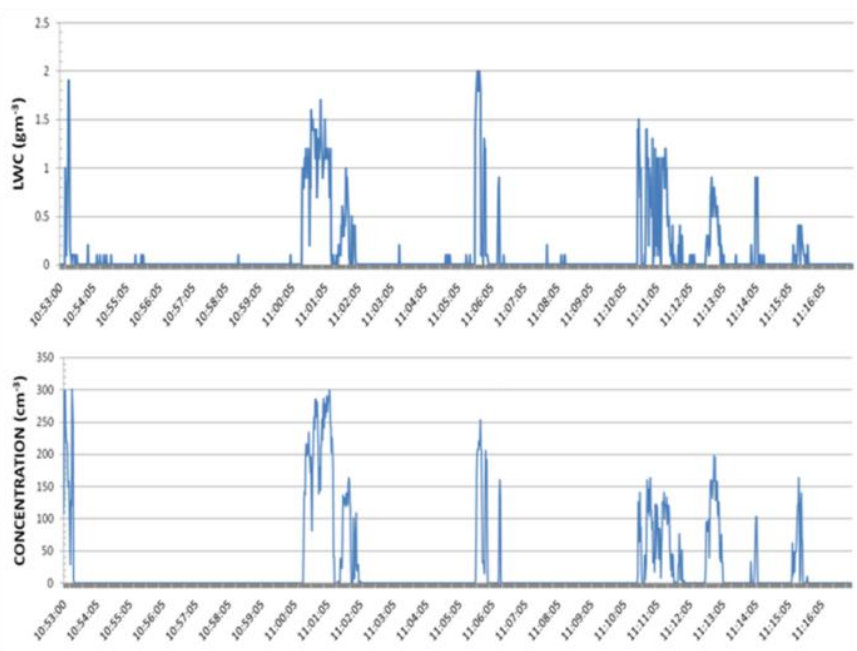

Fig. 5: (Top) Evolution of Liquid Water Content and (Bottom) of the Total Concentration Number of Cloud Droplet Measured by the FSSP Probe During the Cloud Penetration.

Based on the precedent results, it appears clear that variations in the liquid water content are directly related to fluctuations of temperature and vertical speed but mainly to the concentration number of cloud particles.

Analysis of drop size distribution of particles imaged by the different sensors reveals that, for cloud droplets measured by the FSSP probe in the range of 2 and $44 \mu \mathrm{m}$, a high concentration of particles are recorded at the first five intervals covering cloud particles with diameters ranging from 2 to $17 \mu \mathrm{m}$. The analysis also shows a single mode structure centered on diameters in the range of 11 to $14 \mu \mathrm{m}$ with a maximum concentration of $385 \mathrm{~cm}^{-3}$ (Fig.6). The recorded values of the concentration number are consistent by those reported in the literature for a maritime cumulus clouds (Hobbs et al. 1980, Hobbs \& Rangno 1985). 


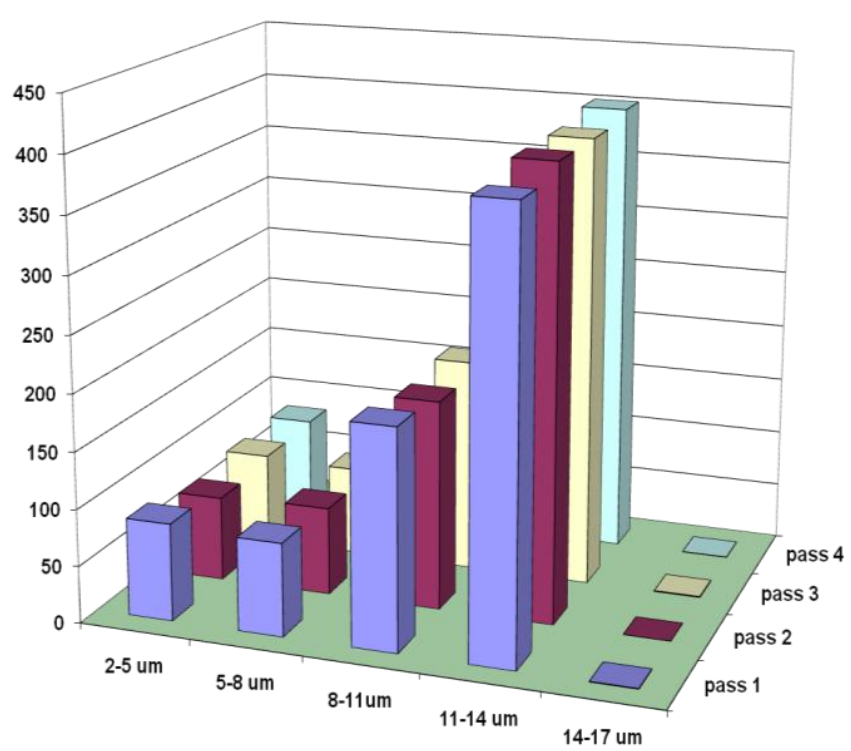

Fig. 6: Drop Size Distribution As Measured By the FSSP Probe. The Graph Represents the Mean of the Total Concentration Number $\left(\mathrm{Cm}^{-3}\right)$ For Each Pass and for Each Range.

The derived mean volume diameter MVD of cloud particles oscillated during the various passes between 10 and $11.5 \mu \mathrm{m}$ with a minimum of $9.3 \mu \mathrm{m}$ and a peak of $12.7 \mu \mathrm{m}$.

\subsection{Case study of deep convective clouds forming dur- ing monsoon season in the region of Sahel}

The following case study documents microphysical characteristics of cumulus congestus and calvus cumulus clouds formed during Mansoon season in the Sahel region and precisely in Burkina Faso. The first case was studied in the beginning of the monsoon season and the second at the end of this rainy season.

\subsubsection{Description of the synoptic meteorological situation}

The analysis of the weather conditions of the day of June 26, 2005 in Burkina Faso is characterized by the persistence, at the surface, of Saharan low pressure area (1007 Hpa) which is centered on the South of Algeria, Mauritania and the central part of Mali while touching the north of Burkina Faso.

In the lower atmospheric layers, the wind trajectories at the pressure level of $850 \mathrm{hPa}$ shows the presence of two vortices located respectively on the South of Mali/West of Burkina and the South of Mauritania which indicates a convergence activity in the lower atmospherics layers leading to the formation of deep convection activity during the day.

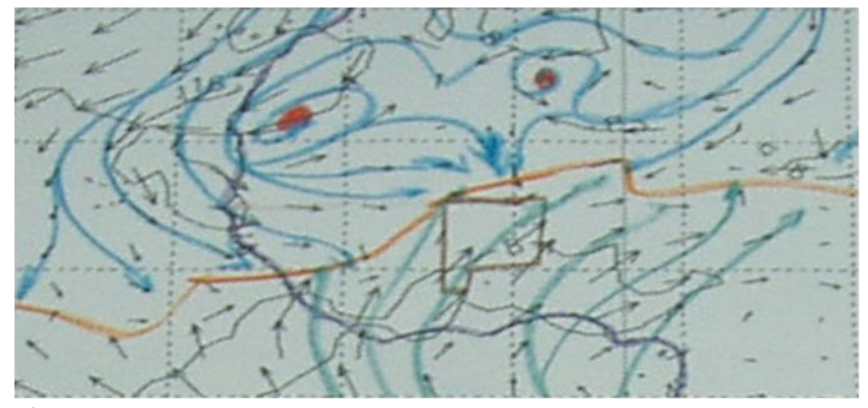

Fig. 7: Monsoon Flow Penetration (Solid Green Lines), Position of the Inter-Tropical Convergence Zone (ITCZ) (Solid Brown Line) Plotted on the Analysis Map of 925hpa Meteorological Chart for June 26 at 12:00. The Square in the Center Mark Out the Position of Burkina Faso.

In Altitude, and specifically at the $700 \mathrm{hPa}$ pressure levels, we note the presence of easterlies waves located in Mali, Senegal, Mauritania and south of Algeria. Burkina Faso is also under the effect of those tropical waves.

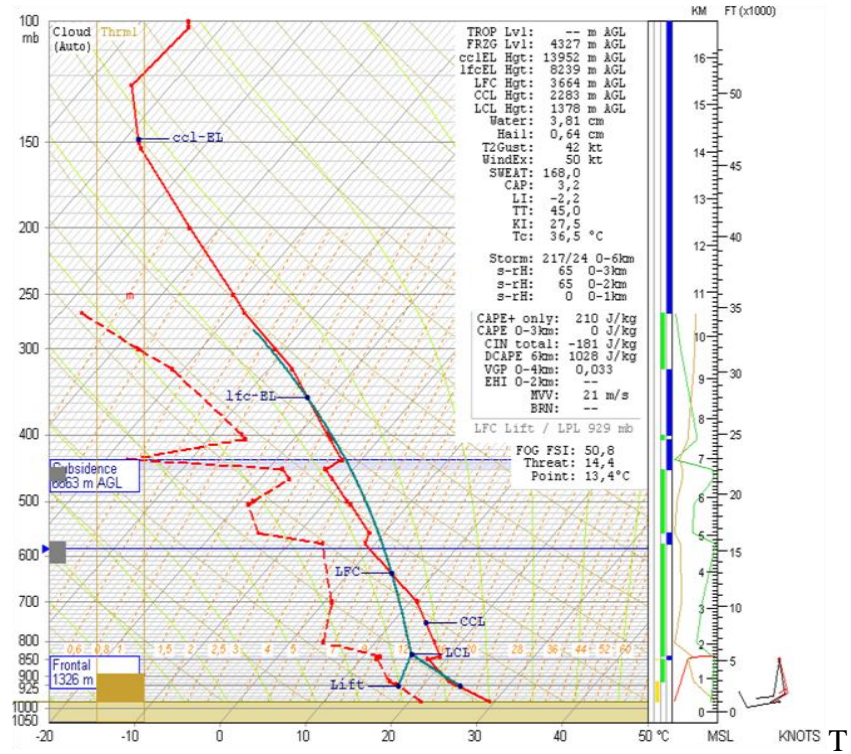

Fig. 8: Atmospheric Sounding of Ouagadougou Taken the 26 June 2005 at $00 \mathrm{~h} 00$.

His most important parameter for the weather forecast purposes is the determination of the Inter-tropical Convergence Zone (ITCZ) border that defines the area and the intensity of the penetration of the monsoon in the African sub-Saharan and tropical countries. The layout of the weather chart and the analysis of wind observations in altitude (at the pressure level of $925 \mathrm{hPa}$ : weather observations derived from Pilot messages) shows a peak of ITCZ reaching latitudes of $23^{\circ} \mathrm{N}$ in the north of Mali and bending at latitude of $19^{\circ} \mathrm{N}$ in the Niger (Fig.7). The monsoon flow is moderate on Burkina Faso and will be more important in the next 24 hours.
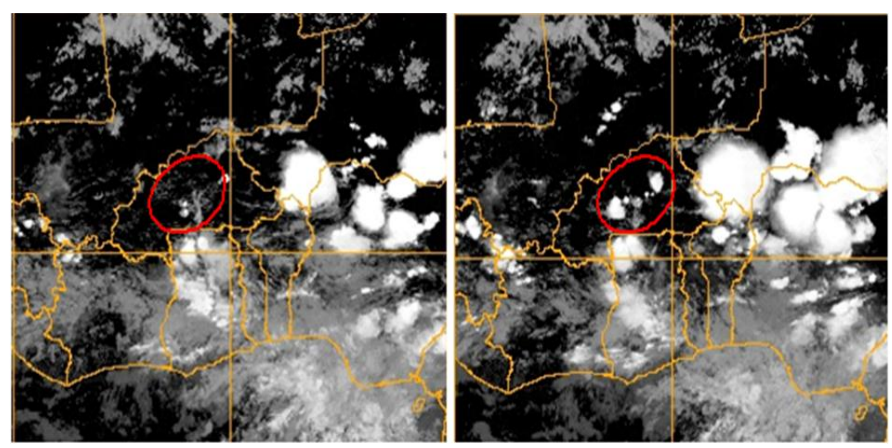

16h45 (Right).

Analysis of the atmospheric sounding of Ouagadougou (Fig.8) shows the presence of an unstable air mass from the lower layers to the pressure level of $440 \mathrm{Hpa}$ (altitude of about $7 \mathrm{~km}$ ) below a layer of subsiding air. In higher atmosphere layers, convectively unstable air is located between pressure levels of $320 \mathrm{hPa}$ and 270 Hpa surmounted by stable and subsiding air. Cloud base is estimated at $1200 \mathrm{~m}$. This situation will promote the formation and the development of convective clouds with a summit reaching $4300 \mathrm{~m}$ and $8200 \mathrm{~m}$. However, deep convection is expected leading to the formation of cumulonimbus with summit exceeding $14500 \mathrm{~m}$. The altitude of the isotherm $0^{\circ} \mathrm{C}$ is $4327 \mathrm{~m}$ and the isotherm $-5^{\circ} \mathrm{C}$ at $5503 \mathrm{~m}$.

\subsubsection{Flight information}

As expected, unstable convective clouds appears at $13 \mathrm{H} 50$ in the central part of the Burkina Faso country with weather radar reflectivity exceeding 30dbz. The research aircraft laboratory King Air 200 takeoff took place at $15 \mathrm{H} 03$ targeting the different cells detected on both sides of the weather radar of Ouagadougou in a radius of 100km (Fig.9). 
During the 112 minutes of flight, ten cumulus congestus were sampled over the area between Ouagadougou and Koudougou on radial varying between $210^{\circ}$ and $270^{\circ}$ and a maximum distance 80 $\mathrm{km}$ from Ouagadougou airport (Fig.10). The passes were conducted at altitudes between $4900 \mathrm{~m}$ and $6200 \mathrm{~m}$ and at temperatures between $+2^{\circ} \mathrm{C}$ and $-5^{\circ} \mathrm{C}$.

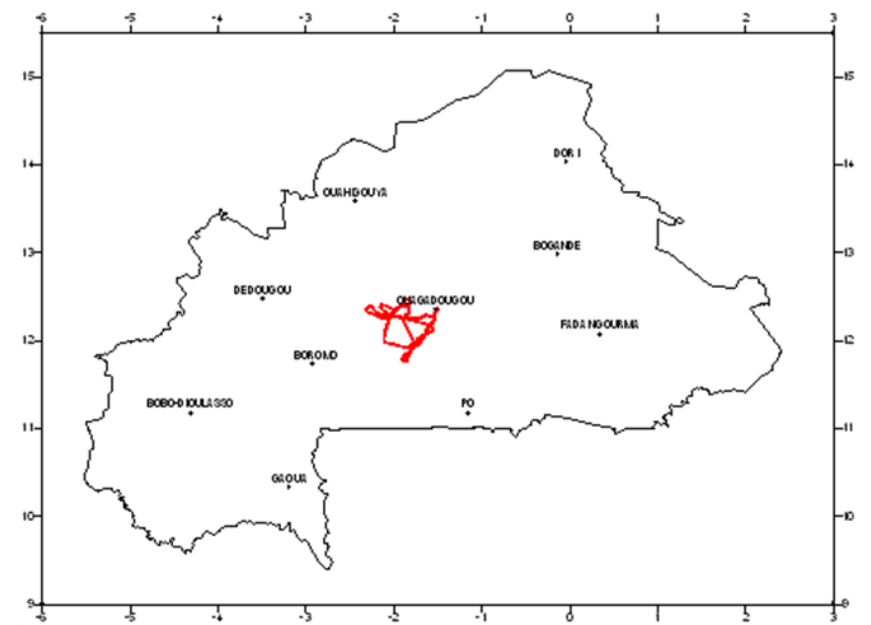

Fig. 10: A Plot of the Flight Tracks for the Flight of June 26, 2005.

\subsubsection{Evolution of cloud microphysical parameters}

Table 2 summarize the microphysical parameters recorded during six of the ten passes and Fig.11 Represents measured values of liquid water content obtained using the LWC MDT sensor and also those derived from the FSSP data during the different passes in the convective clouds. The liquid water content estimated from FSSP measurements is generally lower than that measured directly by the LWC sensor. This remark was also made by Rosenfeld et al, 2006 indicating that the FSSP grossly underestimated the integrated LWC with respect to the DMT sensor. The gap is observed when FSSP operates at values of True Air Speed (TAS) exceeding $160 \mathrm{~m} / \mathrm{s}$ (Rosenfeld et al, 2006 and Freud et al. 2005) or is explained by misalignment of the optics having as a result a reduction of the volume of air sampled.

Table 2: Statistics (Min, Max and Geometrical Mean) of the Different Microphysical Parameters Collected During Six Cloud Penetrations (Nc: Total Concentration Number of Cloud Droplet Measured by the FSSP Probe in the Range of 2-44 Mm and Np the Total Concentration Number of Precipitation Water Drops Measured by the 2DC Probe in the Range of 25-800 Mm)

\begin{tabular}{|c|c|c|c|c|c|c|}
\hline Pass & Altitude (m) & $\mathrm{T}\left({ }^{\circ} \mathrm{C}\right)$ & $\operatorname{LWC}\left(\mathrm{g} / \mathrm{m}^{3}\right)$ & MVD in $\mu \mathrm{m}$ & Nc- FSSP $\left(\mathrm{cm}^{-3}\right)$ & Np -2DC (litre $\left.{ }^{-1}\right)$ \\
\hline & 4860 & 0.80 & - & 22.80 & - & - \\
\hline \multirow[t]{3}{*}{ P1 } & 4879 & 2.50 & 1.50 & 25.70 & 65.70 & 1477.20 \\
\hline & 4866 & 1.95 & 0.93 & 24.58 & 48.44 & 848.57 \\
\hline & 6143 & 0.00 & - & - & - & - \\
\hline \multirow[t]{3}{*}{ P3 } & 6157 & 2.50 & 1.50 & 26.20 & 65.70 & 1477.20 \\
\hline & 6149.2 & - & 0.44 & 19.70 & 20.53 & 678.19 \\
\hline & 5945 & -6.80 & - & 23.50 & - & - \\
\hline \multirow[t]{2}{*}{ P4 } & 5989 & -2.70 & 2.00 & 25.20 & 77.5 & 1709.20 \\
\hline & 6030 & -4.60 & - & 21.60 & - & - \\
\hline \multirow[t]{3}{*}{ P5 } & 6046 & -3.50 & 2.50 & 24.70 & 64.60 & 2298.50 \\
\hline & 6037.6 & - & 0.95 & 23.42 & 28.92 & 902.82 \\
\hline & 5258 & -0.50 & - & - & - & - \\
\hline \multirow[t]{3}{*}{ P9 } & 5308 & 1.90 & 1.00 & 25.00 & 62.60 & 866.40 \\
\hline & 5294.4 & - & 0.61 & 22.91 & 32.08 & 483.65 \\
\hline & 4918 & 0.50 & - & 4.90 & - & - \\
\hline P10 & 4878 & 3.50 & 2.90 & 24.10 & 111.1 & 1300.10 \\
\hline
\end{tabular}

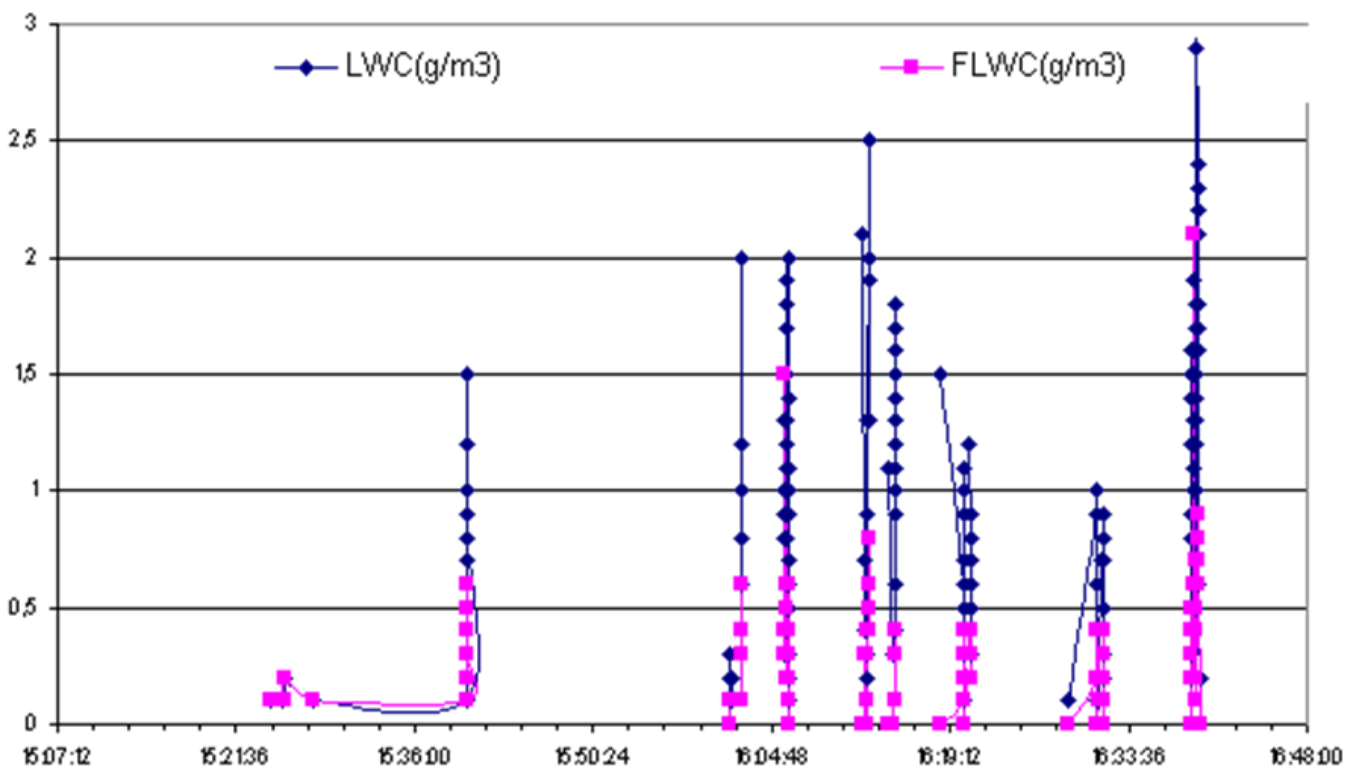

Fig. 11: Measured Values of Liquid Water Content $\left(\mathrm{Gm}^{-3}\right)$ Measured by the DMT Sensor and those Estimated by the FSSP Probe. 


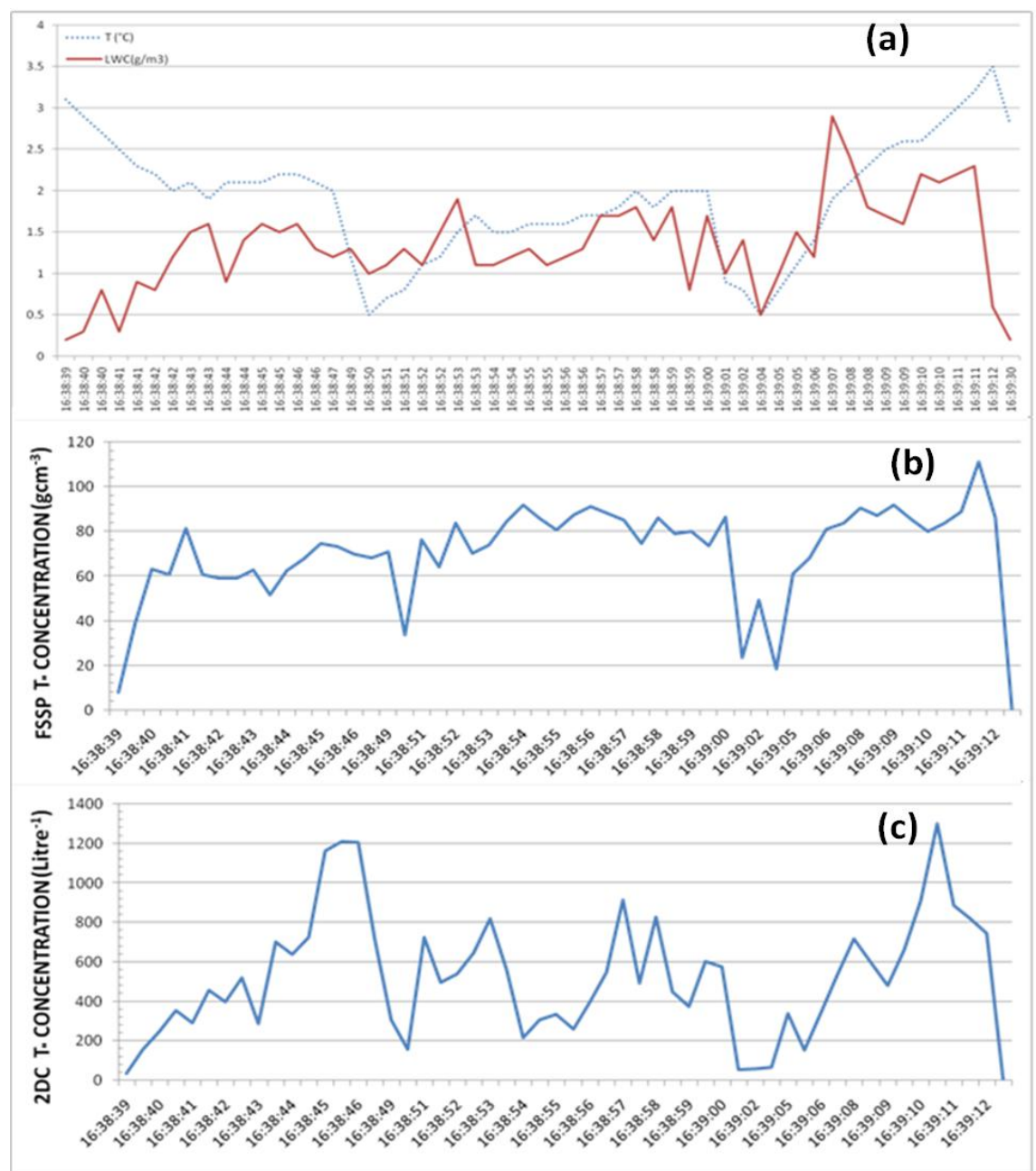

Fig. 12: Evolution, During the Last Pass, of Liquid Water Content in $\mathrm{Gm}^{-3}$ (Red Solid Line); of Temperature in ${ }^{\circ} \mathrm{C}$ (Blue Solid Line) (A); of the FSSP Total Concentration Number (B) and the 2DC Total Concentration Number (C).

Fig12 Illustrates the Evolution of Some Microphysical Characteristics (Liquid Water Content, Temperature, FSSP Total Concentration Number and the 2DC Total Concentration Number) of the Cumulus Congestus Penetrated During the Last Pass at the Altitude of $4900 \mathrm{~m}$.

It appears clear that the increase of the liquid water content (LWC) coincided with a decrease in temperature, but also with an increase in the number of cloud droplets. During this cloud penetration the mean volume diameter (MVD) varied between $22.2 \mu \mathrm{m}$ and $24.1 \mu \mathrm{m}$.

Fig. 13 shows images of the 2DC optical probe and instantaneous particle spectrum detected by the FSSP spectrometer probe. The images were selected for negative temperatures (passes 1 and 4) and positive temperatures for pass $\mathrm{N}^{\circ} 10$.

In these images, forms and shapes of cloud particles could be distinguished. The drops in the liquid phase have a spherical shape while ice particles have irregular shapes in column or flat shapes. It's also possible to distinguish the size and the dimension of the particles and to estimate the proportion of small particles from those having a precipitation size. The FSSP particle spectrum illustrates the distribution of the number of particles by interval of size ( 15 intervals of $5 \mu \mathrm{m}$ each covering the range from $2 \mu \mathrm{m}$ to 44 $\mu \mathrm{m})$.

In this case of study, cloud particles in the liquid phase (positive temperature during the pass $\mathrm{N}^{\circ} 10$, panel (d)) have spherical shape but with small dimensions ranging from 2 to $32 \mu \mathrm{m}$. Lower concentrations are observed for cloud particles having diameters in the range from 32 to $38 \mu \mathrm{m}$.

For images taken in negative temperatures, small concentrations of very small graupel are recorded in panel (a) and some larger graupel particles, with size less than $1 \mathrm{~mm}$, are also observed in panels (a) and (b). Supercooled water drops are also present in the three panels (a) to (c) but high concentrations are recorded in the panel (c).

\subsection{Case Study of deep convective clouds forming dur- ing Monsoon season at the Sahel region}

The research flight of 30 August 2005 operates in full monsoon season and interested warm cumulus clouds with low vertical extension. The meteorological situation of this day was marked by the presence of more stable weather after the passage two days ago of a very large squall line that cover the hole of the Burkina Faso territory. This situation is characterized by the development of warm convective clouds such as cumulus clouds on the whole country and in particular in the central part.

The flight took place between 4:55 and 18.15 p.m. During the flight, several cumulus clouds having basis heights around $600 \mathrm{~m}$ from the ground were penetrated. The various passes were made at altitudes between 800 and $2300 \mathrm{~m}$ above the ground.

\subsubsection{Evolution of cloud microphysical parameters}

As illustrated in Table 3 and Fig.14, mean temperatures encountered during the different passes varied between $12^{\circ} \mathrm{C}$ and $21^{\circ} \mathrm{C}$. Liquid water content was in general lower than $1 \mathrm{gm}^{-3}$ with peak values reaching $2 \mathrm{gm}^{-3}$.

Analysis of drop size distribution of cloud particles measured by the $2 \mathrm{DC}$ probe shows that the maximum values of the total concentration of cloud particles measured varied between 65 and 120 per litre. The cloud particles sampled were large having a mean volume diameter ranging from $13 \mu \mathrm{m}$ and $26 \mu \mathrm{m}$. 

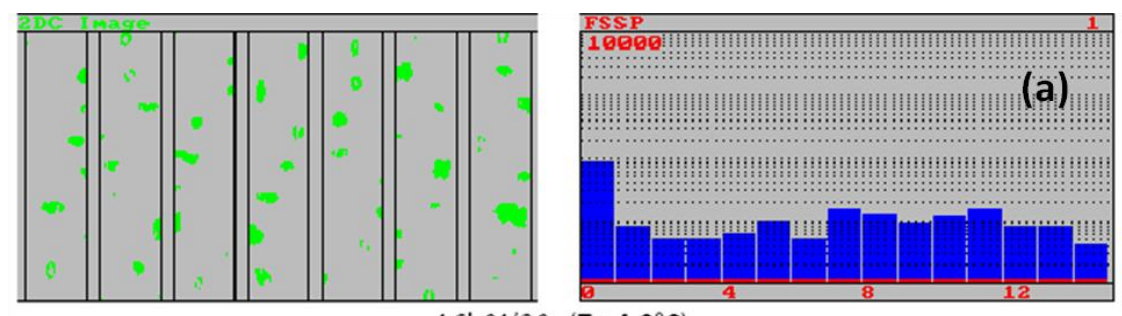

$16 \mathrm{~h} 01^{\prime} 20 \mathrm{~s}\left(\mathrm{~T}=-4.9^{\circ} \mathrm{C}\right)$
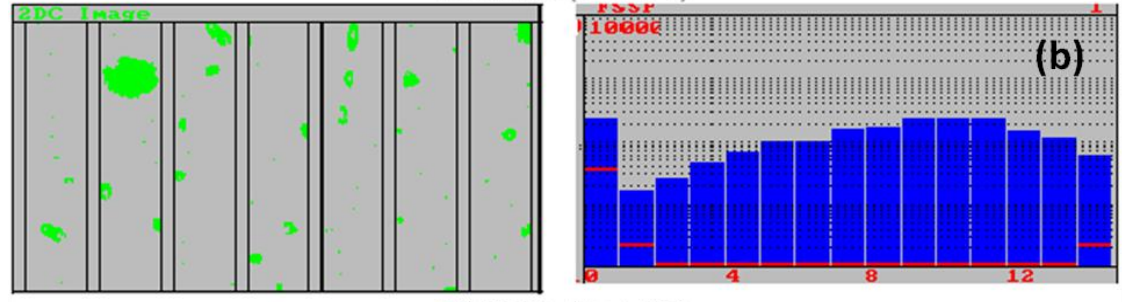

$16 \mathrm{~h} 01^{\prime} 29 \mathrm{~s}\left(\mathrm{~T}=-4.6^{\circ} \mathrm{C}\right)$

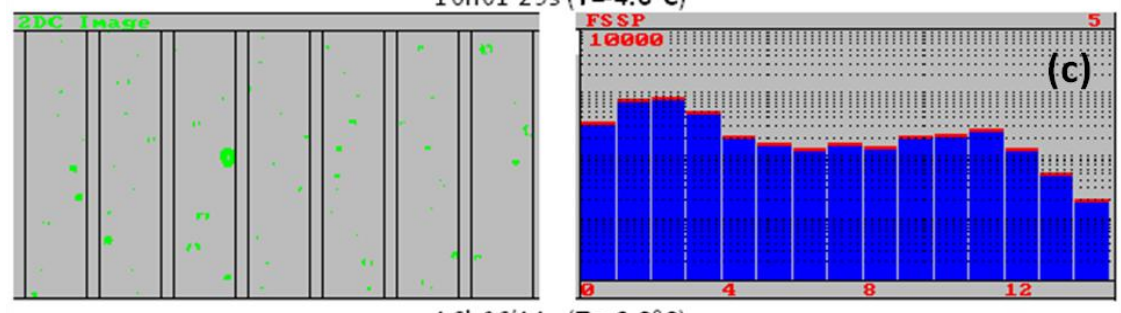

$16 \mathrm{~h}^{\prime} 6^{\prime} 11 \mathrm{~s}\left(\mathrm{~T}=-6.8^{\circ} \mathrm{C}\right)$
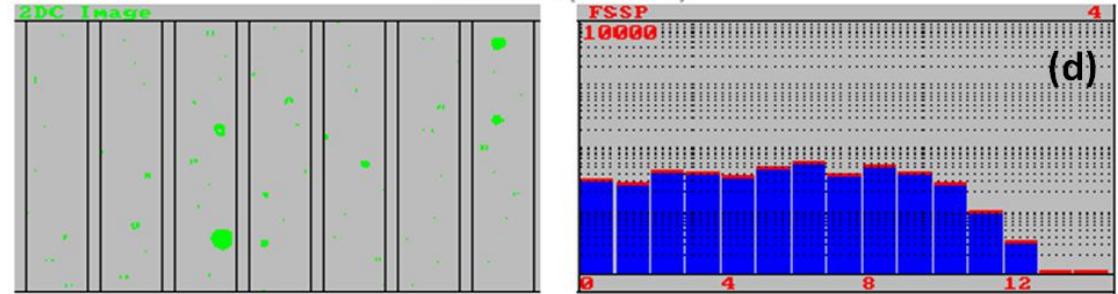

$16 \mathrm{~h}^{\prime} 8^{\prime} 39 \mathrm{~s}\left(\mathrm{~T}=+3.1^{\circ} \mathrm{C}\right)$

Fig. 13: Examples of 2DC Probe Images and FSSP Instantaneous Particle Spectrum Taken at Different Times and Different Temperatures during the Individual Clouds Penetrations. The Width Step in Each 2DC Image Is $0.8 \mathrm{Mm}$ and The FSSP Spectrum Is Established for 15 Channels in the Range of $2 \mu \mathrm{m}$ to $44 \mathrm{Mm}$.

Table 3: Statistics (Geometrical Mean and Maximum) of Some Microphysical Parameters Collected During Cumulus Penetrations

\begin{tabular}{|c|c|c|c|c|c|}
\hline Pass & Pressure $(\mathrm{hPa})$ & $\mathrm{T}\left({ }^{\circ} \mathrm{C}\right)$ & $\operatorname{LWC}\left(\mathrm{g} / \mathrm{m}^{3}\right)$ & MVD in $\mu \mathrm{m}$ & 2DC-TC $\left(\right.$ litre $\left.^{-1}\right)$ \\
\hline \multirow{2}{*}{ P1 } & 910.5 & 20.77 & 0.17 & 12.95 & 68.7 \\
\hline & 910.9 & 20.80 & 0.30 & 14.00 & 101.6 \\
\hline \multirow{2}{*}{ P3 } & 845.8 & 16.96 & 0.26 & 16.09 & 34.1 \\
\hline & 846.7 & 17.30 & 0.70 & 20.20 & 73.2 \\
\hline \multirow{2}{*}{ P4 } & 814.5 & 16.09 & 0.88 & 22.59 & 58.37 \\
\hline & 814.8 & 16.5 & 1.20 & 23.10 & 84.6 \\
\hline \multirow{2}{*}{ P6 } & 893.0 & 20.12 & 0.38 & 14.86 & 55.8 \\
\hline & 894.2 & 20.70 & 0.70 & 17.00 & 120.4 \\
\hline \multirow{2}{*}{ P7 } & 893.5 & 19.80 & 0.20 & 13.20 & 47.0 \\
\hline & 894.0 & 20.00 & 0.50 & 17.10 & 81.5 \\
\hline \multirow{2}{*}{ P8 } & 859.6 & 17.88 & 0.30 & 13.77 & 56.9 \\
\hline & 861.2 & 18.60 & 1.30 & 19.90 & 109.6 \\
\hline \multirow{2}{*}{ P10 } & 829.9 & 16.43 & 0.55 & 20.57 & 41.5 \\
\hline & 831.7 & 16.90 & 1.80 & 24.20 & 84.7 \\
\hline \multirow{2}{*}{ P11 } & 799.3 & 14.60 & 0.82 & 22.71 & 46.0 \\
\hline & 800.3 & 15.20 & 1.80 & 27.20 & 91.6 \\
\hline \multirow{2}{*}{ P12 } & 768.6 & 12.77 & 0.70 & 23.95 & 42.9 \\
\hline & 769.6 & 13.90 & 2.10 & 26.70 & 84.0 \\
\hline \multirow{2}{*}{ P13 } & 741.8 & 11.58 & 1.00 & 24.22 & 46.7 \\
\hline & 742.7 & 13.00 & 2.00 & 26.50 & 73.3 \\
\hline
\end{tabular}




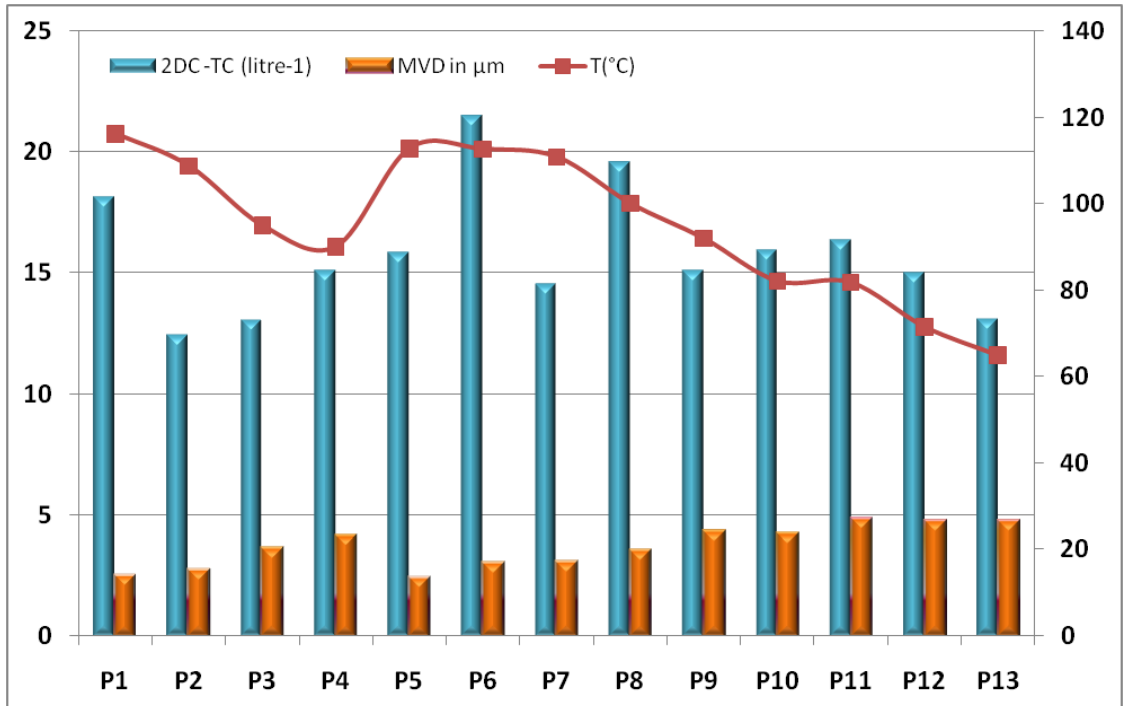

Fig. 14: Evolution, During the Different Passes, of the Mean Values of Temperature in ${ }^{\circ} \mathrm{C}$ (Solid Red Line) and the Maximum Values of the Mean Volume Diameter in Mm (Orange Colour Bars) and the Total Concentration Number Per Litre Measured by the 2DC Probe (Blue Bar).

The measurements recorded by the FSSP probe indicate that the total concentration number did not exceed $73 \mathrm{~cm}^{-3}$ obtained for the range of 5 to $8 \mu \mathrm{m}$. Plots of the averaged cloud particle spectrum for each pass show the existence of two peaks. The first obtained for diameters between 5 and $8 \mu \mathrm{m}$ with mean total concentration number of $31 \mathrm{~cm}^{-3}$ and maximums varying in most cases between 40 and $70 \mathrm{~cm}^{-3}$ and the second for particles ranging between 11 and $14 \mu \mathrm{m}$ with mean total concentration number of $23.4 \mathrm{~cm}^{-3}$ varying between 30 and $50 \mathrm{~cm}^{-3}$. Large particles with diameters ranging between 17 and 26 are also present with weak concentrations varying between 7 and $15 \mathrm{~cm}^{-3}$.

\section{Conclusion}

In this paper we have described some of the microphysical characteristics of midlevel cumulus clouds formed in both marine and continental environments. In situ measurements are obtained using instrumental aircrafts.

Several passes were made at the top of the sampled clouds and reported data were collected and analysed describing the variability of the measured parameters at various altitudes and thus different temperature values (negative and positive temperatures). The dependency of the liquid water content to the temperature has been studied but also its variation with regard to the vertical velocity and to the total concentration number of cloud particles. It appears clear that the increase of liquid water content is accompanied by a decrease in temperature and an increase of mixing ratio. The variation in the liquid water content is directly related to fluctuations of temperature and vertical velocity but mainly to the concentration number of cloud particles.

The liquid water content estimated from FSSP measurements is generally lower than that measured directly by the LWC sensor. The concentrations of particle clouds and their distribution described for the three case studies are consistent with similar measurements collected in several parts of the world and in particular in tropical zone.

\section{Acknowledgments}

The present work was conducted thanks to joint efforts of the scientific, operational and managerial teams of the national weather modification programs in Morocco and Burkina Fasso. I'm deeply grateful to all colleagues in Morocco and in Burkina Fasso and my personal thanks are addressed to all of them. Efforts and great experience of aircraft pilots and technical staff are also recognized for the success of the measurement activities.

\section{References}

[1] Fleishauer R P, Larson V E \& Voner Haar T H, (2002) Observed Microphysical structure of midlevel, mixed-phase Clouds. J. Atmos. Sci., 59, 1779-1804. http://dx.doi.org/10.1175/1520-0469 (2002)059<1779: OMSOMM>2.0.CO; 2.

[2] Cotton W R \& Anthes R A (1989) the mesoscale structure of extratopical cyclones and middle and high clouds. Storm and Cloud Dynamics, International Geophysical Series, vol 44, Academic Press, 745-787.

[3] Gultepe I, Isaac G a \& Cober S G (2002) Cloud microphysical characteristics versus temperature for three Canadian field projects, Annales Geophysicae, 20, 1891-1898.Gultepe I \& Isaac G A (2004) Aircraft observations of cloud droplet number concentration: Implications for climate studies, Q. J. R. Meteorol. Soc, 130, 2377-2390. http://dx.doi.org/10.1256/qj.03.120.

[4] Gultepe I, Isaac G A, Leaitch W R \& Banic C (1996) Parameterizations of marine stratus microphysics based on in-situ observations: Implications for GCMs. J. Climate, 9, 345-357. http://dx.doi.org/10.1175/1520-0442 (1996)009<0345: POMSMB $>2.0 . \mathrm{CO} ; 2$.

[5] Randall D, Curry J, Battisti D, Flato G, Grumbine R, Hakkinen S, Martinson D, Preller R, Walsh J \& Weatherly J (1998) Status of and outlook for large-scale modeling of atmosphere- ice-ocean interactions in the Arctic, Bull. Am. Meteorol. Soc, 79, 197-209. http://dx.doi.org/10.1175/1520-0477

(1998)079<0197: SOAOFL $>2.0 . \mathrm{CO} ; 2$

[6] Rodgers R R \& Yau M K (1996) A Short Course in Cloud physics, 3rd ed. Pergamon Press, Oxford.

[7] Frey W, Borrmann S, Kunkel D, Weigel R, de Reus M, Schlager H, Roiger A, Voigt C, Hoor P, Curtius J, Kramer M, Schiller C, Volk C M, Homan C D, Fierli F, Donfrancesco G Di, Ulanovsky A, Ravegnani F, Sitnikov N M, Viciani S, D'Amato F, Shur G N, Belyaev G V, Law K S \& Cairo F (2011) In situ measurements of tropical cloud properties in the West African Monsoon: upper tropospheric ice clouds, Mesoscale Convective System outflow and subvisual cirrus, Atmos. Chem. Phys, 11, 5569-5590. Hobbs P V \& Rangno A L (1985) Ice particle concentrations in clouds, J atmospheric sciences, vol 42, 2523-2549.

[8] Hobbs P V, Politovich M K \& Radke L F (1980) structure of summer convective clouds in eastern Montana, I. Natural clouds, J. Appl. Meteor, $\quad 19$, 645-663. http://dx.doi.org/10.1175/1520-0450 (1980)019<0645: TSOSCC>2.0.CO; 2. 